\title{
High-temperature deformation of delta-processed Inconel 718
}

\author{
Pedro Páramo-Kañetas ${ }^{(1,2, *)}$, Utkudeniz Özturk ${ }^{(2)}$, Jessica Calvo ${ }^{(2)}$, José María Cabrera ${ }^{(2)}$ and Martha \\ Guerrero-Mata ${ }^{(1)}$ \\ (1) Universidad Autónoma de Nuevo León, Facultad de Ingeniería Mecánica y Eléctrica, Av. Universidad s/n, Cd. \\ Universitaria, 66451 San Nicolás de los Garza, Nuevo León, Mexico. \\ (2) Departamento de Ciencia de los Materiales e Ingeniería Metalúrgica, Universitat Politècnica de Catalunya, Av. Eduard \\ Maristany 10-14, 08019-Barcelona, Spain
}

\begin{abstract}
The following paper explores the hot-flow behavior of Inconel 718 subjected to delta processing (DP), with various microstructures obtained by means of carrying out an initial billet forging operation prior to the heat treatment and final deformation tests. Hot compression tests were subsequently performed at 960 ${ }^{\circ} \mathrm{C}$ and $1020{ }^{\circ} \mathrm{C}$ at the four different strain rates of $0.001,0.01,0.1$, and $1 \mathrm{~s}^{-1}$. The two deformation temperatures recorded-were $960^{\circ} \mathrm{C}$ and $1020^{\circ} \mathrm{C}$, located below and above the $\delta$-solvus of IN718 respectively. Microstructural characterization was performed by means of optical (OM) and scanning electron microscopy (SEM).
\end{abstract}

SEM examinations suggest that the existence of the $\delta$-phase prior to the application of the high deformation temperature may results in the fragmentation of the existing $\delta$-phase by means of partial dissolution and/or deformation, leading to an improved grain size control.

The-A general-classic dynamic recrystallization (DRX) behavior was observed in the flow curves, which is typical of low-medium stacking fault energy (SFE) alloys, with-This flow behavior was modeled according to various approaches and the results compared. Peak stress modeling was performed using two different approaches, referred to as 'apparent' and 'physically-based'. The hot-flow behavior before the peak stress was modeled according to the Estrin-Mecking-Bergstrom approach, with Avrami kinetics employed to describe the DRX behavior.

Keywords: Inconel 718; delta processing; physically-based approach.

*Corresponding author. Departamento de Ciencia de los Materiales e Ingeniería Metalúrgica, Universitat Politècnica de Catalunya, Av. Eduard Maristany 10-14, 08019-Barcelona, Spain.

E-mail address: pedro.jacinto.paramo@upc.edu (Pedro Páramo-Kañetas) 


\section{INTRODUCTION}

Nickel-based superalloys are widely used in the aerospace and power generation industries due to their excellent mechanical properties at elevated temperatures and good corrosion resistance, with being Inconel 718 (a.k.a. IN718, alloy 718) one of the most successful alloys. While it is well known that the mechanical properties of this alloy are strongly affected by the microstructure and especially the grain size, achieving a uniform grain size in IN718 and similar alloys has always proved a challenge for hot forming process designers.

A sound strategy for obtaining a more uniform grain size throughout the workpiece is referred to as 'delta processing' or 'DP', whereby precipitation of the $\delta$-phase prior to hot deformation is promoted, helping result in better grain size control during the deformation process. It is well known that the presence of $\delta$-phase particles can hinder grain growth through Zener pinning. Hongbo and Gaochao (2015) have concluded that it is possible to obtain a finer and more uniform grain structure when the forging, $\delta$-phase precipitation, and recrystallization heat treatment steps are applied in series. Cheng et al. (2011) published a work focusing on the multi-stage hot working processes and concluded that grain growth is restrained during the holding period between the steps because of the pinning effect of $\delta$-phase on $\ominus$ the grain boundary $\delta$.

Due to the nature of this pinning mechanism, the amount, size, and morphology of the $\delta$-phase greatly influence the effectivity of grain size control, as well as other mechanical properties. Agnoli et al. (2015), for example, revealed that the distribution of the stored energy within the material with respect to the $\delta_{-}$ phase particle distribution is responsible for microstructural stability during hot deformation. Wang et al. (2009) reported that the co-existence of an undissolved $\delta$-phase and the ductile region near these $\delta$ particles (due to the denuded zone of $\gamma$ " phase) may relax the stress concentration at grain boundaries, helping retard grain boundary crack initiation and propagation.

During delta processing, the $\delta_{--}$-phase obtained prior to deformation may locally fracture and/or partially dissolve during the hot deformation process, resulting in a finer $\delta$ structure which further facilitates the control of grain growth. It must also be mentioned that the plasticity of the alloy decreases at elevated temperatures as the content of the $\delta$-phase increases, as reported by Zhang et al. (2010). The morphological state of $\delta$ is also just as important as the amount. On this subject, Ning et al. (2015) reported that while the plasticity of the rod-shaped $\delta$ is good, the needle-like $\delta$ contributes to increase strength and to reduces ductility.

Apart from inhibiting the growth of the existing grains, the $\delta$-phase also exerts a highly positive effect on the alloy's dynamic recrystallization (DRX) behavior. Wang et al. (2011) concluded that depending on its size, distribution, and morphology, the $\delta$-phase may serve as nucleation sites for the new strain-free grains, facilitating the DRX initiation and therefore offering an extra mechanism to promote the onset of DRX.

In order to design better forming processes, optimize final product properties, and reduce manufacturing costs, reliable experimental data and suitable mathematical models areis required to on hot flow behavior as are suitable mathematical models which-describe the hot flow behavior this behavior

Con formato: Sin Resaltar

\begin{tabular}{l}
\hline Con formato: Sin Resaltar \\
\hline Con formato: Sin Resaltar \\
\hline Con formato: Sin Resaltar \\
\hline Con formato: Sin Resaltar \\
\hline Con formato: Sin Resaltar \\
\hline Con formato: Sin Resaltar \\
\hline Con formato: Sin Resaltar \\
\hline Con formato: Sin Resaltar \\
\hline
\end{tabular}

\begin{tabular}{l} 
Con formato: Sin Resaltar \\
\hline Con formato: Sin Resaltar \\
Con formato: Sin Resaltar \\
Con formato: Sin Resaltar \\
\hline Con formato: Sin Resaltar \\
\hline
\end{tabular}


within engineering tolerances. Generally speaking, the constitutive laws of plastic flow describe the relationship between the deformation parameters (i.e. stress, strain, and strain rate) at a given temperature and a given initial microstructural state. There are a number of recent studies on the hot-forming behavior of IN718 and its modeling. Azarbarmas et al. (2016) investigated the hot compression behavior of IN718 and proposed a model based on a general constitutive equation originating from the approach by Sellars and Tegart (1966). Si et al. (2015) studied the flow curves for the delta processing of IN718, using the classic hyperbolic-sine approach and Arrhenius expression, reporting material constants for this approach. Lin et al. $(2014,2015-a, 2015-b)$ proposed a viscoplastic material constant model with an isotropic internal variable, including the effect of the $\delta$-phase amount during hot deformation. In addition to these, Hussain et al. (2015) derived a constitutive model based on a double multivariate non-linear regression analysis (DMNR) describing the nonlinear relationship between flow stress and thermo-mechanical parameters.

While hot-deformation behavior is fairly well expressed under constant initial conditions, these mathematical models also require a physical basis in order to render them more versatile under conditions where the initial microstructural state is a variable.

The purpose of this study is to investigate and evaluate the high-temperature deformation behavior of delta-processed IN718. To this end, cylindrical samples with different initial microstructures were processed via DP treatment and microstructural properties tracked before and after the heat treatment step, as well as after the final hot deformation process. Four samples were kept as the control group, with no thermal treatment applied to them. The flow curves were then analyzed and correlations between the microstructural features highlighted. Finally, modeling of the hot-flow behavior was performed based on various approaches including 'physically-based' models.

\section{EXPERIMENTAL PROCEDURE}

A cylindrical billet of Inconel 718 with a height of $150 \mathrm{~mm}$ and a diameter of $100 \mathrm{~mm}$ was used to machine cylindrical samples for compression tests after being subjected to a two-step forging. The first step was conducted to a maximum height of $75 \mathrm{~mm}$ and the second to $40.5 \mathrm{~mm}$.

After the initial forging operation, the billet was cut from the middle plane in the longitudinal direction, with 20 cylindrical samples $7 \mathrm{~mm}$ in diameter and $10 \mathrm{~mm}$ in height extracted from the forged billet. An initial microstructural characterization was then performed on the samples obtained. As the original microstructure is partially recrystallized, samples for the compression tests were extracted from areas of the billet displaying such a feature. A detailed analysis of the initial microstructures of three representative samples is provided in the 'Results \& Discussion' section.

Prior to the compression tests, samples were solutionized at $1100{ }^{\circ} \mathrm{C}$ for one hour and then subjected to an aging treatment at $900{ }^{\circ} \mathrm{C}$ for 24 hours. The heat treatment cycle was then terminated with water quenching. To create a control group, four samples were exempted from the delta process.

The heat-treated samples were compressed at $1020{ }^{\circ} \mathrm{C}$ and $960{ }^{\circ} \mathrm{C}$, with these temperatures above and below $\delta$-solvus for the present alloy respectively, and at strain rates of $0.001,0.01,0.1$, and $1 \mathrm{~s}^{-1}$. A set of 10 tests was carried out, with the tests performed twice. This entire process (heat treatment and deformation) is often referred as "delta processing". The final true strain was set to 0.6 for all samples.

\begin{tabular}{l} 
Con formato: Sin Resaltar \\
\hline Con formato: Sin Resaltar \\
\hline Con formato: Sin Resaltar \\
\hline
\end{tabular}


Parameters for the compression tests and grain size evolution of the samples are summarized in Table 1. The deformed samples were prepared for microstructural investigation following standard routes, with the grain sizes measured according to the ASTM E-112 standard by employing graded maps at 100X.

Table 1. Sample grain size evolution.

\begin{tabular}{|c|c|c|c|c|}
\hline \multicolumn{2}{|c|}{ Testing parameters } & \multicolumn{3}{|c|}{ Grain size average ASTM } \\
\hline $\begin{array}{l}\text { Tempera } \\
\text { ture }\left({ }^{\circ} \mathrm{C}\right)\end{array}$ & $\begin{array}{r}\text { Strain } \\
\text { Rate }\left(\mathrm{s}^{-1}\right)\end{array}$ & After Billet Forging & After DP & $\begin{array}{l}\text { After Compression } \\
\text { Testing }\end{array}$ \\
\hline 960 & 0.001 & 6 ALA 3 & $8-70 \%, 7-30 \%$ ALA 6 & $6-70 \%, 7-30 \%$ ALA 5 \\
\hline (A) 960 & 0.001 & 7 & 3 ALA 2 & $4-70 \%, 5-30 \%$ \\
\hline 1020 & 0.001 & 10 & 3 ALA 2 & $4-90 \%, 8-10 \%$ \\
\hline 1020 & 0.001 & $10-30 \%, 6-70 \%$ ALA 3.5 & 3 ALA 2 & $6-60 \%, 9-40 \%$ ALA 5 \\
\hline 960 & 0.01 & 6.5 ALA 2.5 & $3-60 \%, 4-40 \%$ ALA 2 & $3-70 \%, 4-30 \%$ ALA 2 \\
\hline 960 & 0.01 & $11-90 \%, 8-10 \%$ ALA 6 & 6 ALA 5 & $4-60 \%, 5-40 \%$ \\
\hline 1020 & 0.01 & $11-20 \%, 7-80 \%$ ALA 4 & $3-70 \%, 4-30 \%$ & $4-70 \%, 5-30 \%$ ALA 3 \\
\hline (B) 1020 & 0.01 & $7-70 \%, 6-30 \%$ ALA 5 & 4 ALA 3 & $4-60 \%, 5-30 \%, 10-10 \%$ \\
\hline 960 & 0.1 & $11-30 \%, 7.5-30 \%$ ALA 3.5 & 10 ALA 7 & $7-70 \%, 9-30 \%$ ALA 6 \\
\hline 960 & 0.1 & $9-80 \%, 8-20 \%$ ALA 6 & 4 ALA 2 & $4-70 \%, 5-30 \%$ \\
\hline 1020 & 0.1 & $8-80 \%, 7-20 \%$ ALA 3 & $3-60 \%, 4-40 \%$ ALA 2 & $3-60 \%, 4-40 \%$ ALA 2 \\
\hline 1020 & 0.1 & 10 & 3 ALA 1 & $4-70 \%, 5-30 \%$ \\
\hline 960 & 1 & 6.5 ALA 2 & $5-40 \%, 6-60 \%$ ALA 4 & $5-40 \%, 4-60 \%$ ALA 3 \\
\hline 960 & 1 & $11-40 \%, 8-60 \%$ ALA 5 & 4 ALA 3 & $4-60 \%, 5-40 \%$ \\
\hline 1020 & 1 & $11-10 \%, 6-90 \%$ ALA 3 & 4 ALA 3 & $4-80 \%, 10-20 \%$ \\
\hline (C) 1020 & 1 & $11-30 \%, 8-70 \%$ ALA 5 & 4 ALA 3 & $4-60 \%, 5-40 \%$ \\
\hline$* 960$ & 0.01 & $7-80 \%, 10-20 \%$ ALA 5 & & 10 \\
\hline *960 & 0.01 & $7-70 \%, 10-30 \%$ & & 10 ALA 8 \\
\hline$* 1020$ & 0.001 & 7 ALA 5 & & $7-90 \%, 10-10 \%$ \\
\hline$* 1020$ & 0.001 & 7 ALA 5 & & $7-60 \%, 9-40 \%$ ALA 5 \\
\hline
\end{tabular}

ASTM numbers: $11(8 \mu \mathrm{m}), 10(11 \mu \mathrm{m}), 9(16 \mu \mathrm{m}), 8(22.5 \mu \mathrm{m}), 7.5(27 \mu \mathrm{m}) 7(31 \mu \mathrm{m}), 6.5(38 \mu \mathrm{m}), 6(45 \mu \mathrm{m}), 5(63 \mu \mathrm{m}), 4$ $(90 \mu \mathrm{m}), 3.5(107 \mu \mathrm{m}), 3(127 \mu \mathrm{m}), 2.5(151 \mu \mathrm{m}), 2(180 \mu \mathrm{m}), 1(254 \mu \mathrm{m})$. Example: 9-80\%, 7-20\% ALA 3 means that 80 vol. \% of grains have a size of 9, $20 \mathrm{vol}$. \% have a size of 7, and larger grains with sizes as large aste to 3 were observed.

\section{RESULTS AND DISCUSSION}

\section{Microstructural characterization}

Microstructural analyses were conducted on the samples cut from the billet after the initial forging process, as mentioned above.

As the deformation of the billet during the initial forging operation is not homogeneous, it may be expected that the samples' grain structures display significant differences before delta processing. Three representative samples were selected, with their microstructures upon initial forging given in Fig. 1. An average grain size of 7 ASTM $(31 \mu \mathrm{m})$ is observed in the sample shown in Fig. 1 (a), while in other samples, grains as large as 5 ASTM $(63 \mu \mathrm{m})$ were observed. A summary of the grain size analysis is given in Table 1. This relatively uniform grain size may be associated with the double step billet forging operation. The samples are-shown in Fig. 1 (a), (b), and (c) will hereafter be referred to as samples A, B, and $\mathrm{C}$. 


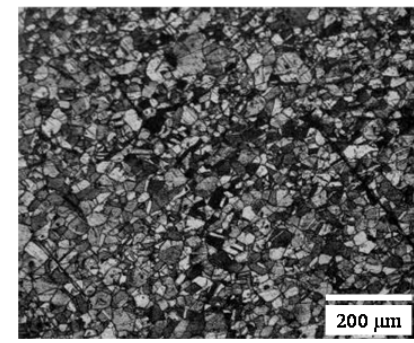

a) Sample A b) Sample B

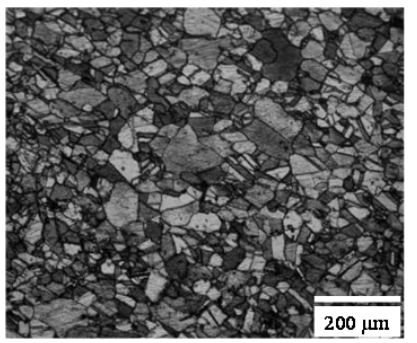

representative samples from different

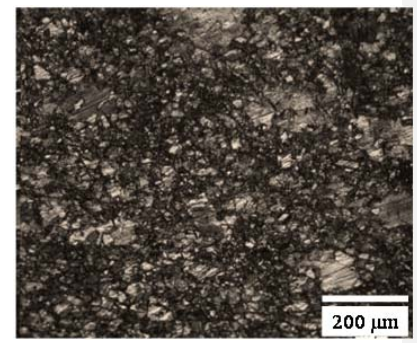

c) Sample C treatment and subsequent deformation)

As expected, the grain size increases after heat treatment, with samples B and C exhibiting a grain size of 4 ASTM $(90 \mu \mathrm{m})$, slightly finer than that of sample A at $(3$ ASTM or $(127 \mu \mathrm{m})$. The micrographs showing the states after heat treatment are summarized in Fig. 2. A high amount of $\delta$-phase may be observed in the samples, measured to be $9 \%$ together with some twin formations.

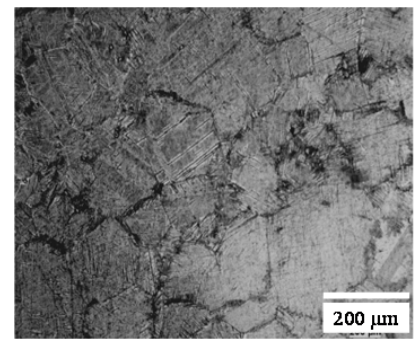

a) Sample A

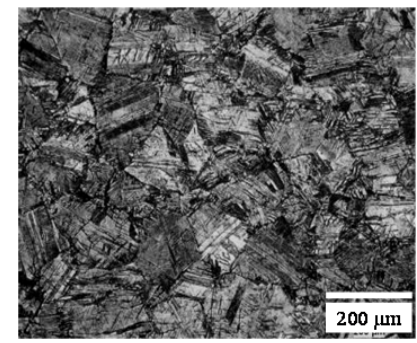

b) Sample B

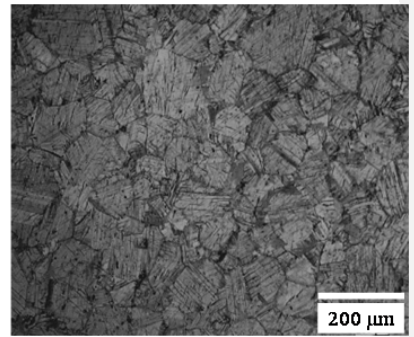

c) Sample C

Figure 2: Microstructures of the representative samples after delta processing.

Microstructures of the same representative samples (A, B, and C) after the hot compression tests are given in Fig. 3. As expected, finer grain structures and higher deformation twins (shorter twins) are generally observed after the deformation instead of annealing twins (larger twins).

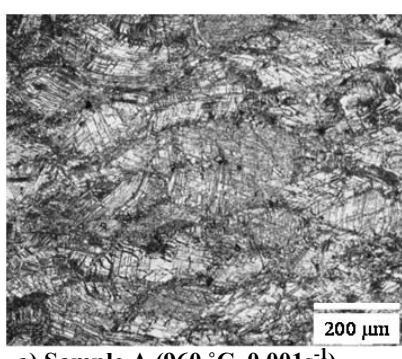

a) Sample A $\left(960{ }^{\circ} \mathrm{C}, 0.001 \mathrm{~s}^{-1}\right)$

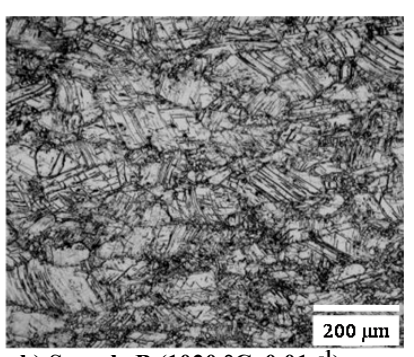

b) Sample B $\left(1020^{\circ} \mathrm{C}, 0.01 \mathrm{~s}^{-1}\right)$

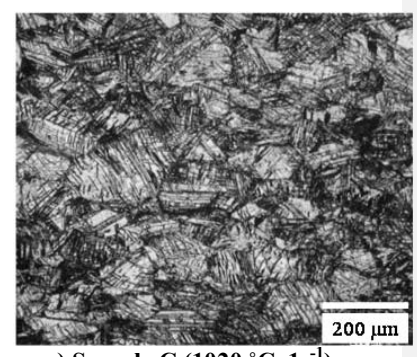

c) Sample $\mathrm{C}\left(1020{ }^{\circ} \mathrm{C}, 1 \mathrm{~s}^{-1}\right)$

Figure 3: Microstructures of the samples upon hot compression tests and details of deformation.

It is well known that in Inconel 718 and similar alloys an excessive amount of $\delta$-phase results in embrittlement; therefore this is generally avoided. When a needle-shaped $\delta$-phase is obtained prior to the 
forming operation, however, the existing $\delta$-phase may be partially re-distributed during the deformation process resulting in a more uniform grain boundary $\delta$-phase structure, thus affording better control over the grain size.

One of the mechanisms of this "partial re-distribution" is the fracture undergone by the $\delta$-phase. This may be observed in the current study on the delta-processed samples in the SEM micrographs presented in Figs. 4 and 5, where the fractured and/or partially dissolved $\delta$-particles are marked with arrows in Fig. 5. The same phenomenon was also highlighted by Zhang et al. (2010).

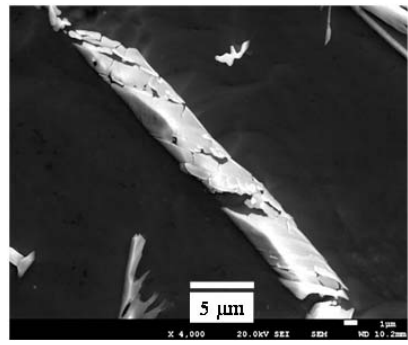

a) Sample A

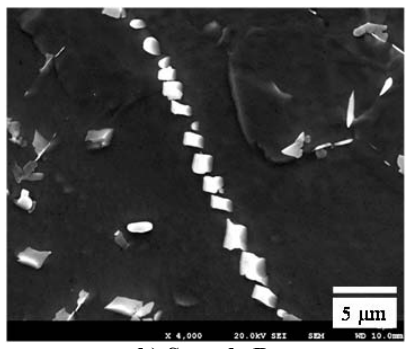

b) Sample B

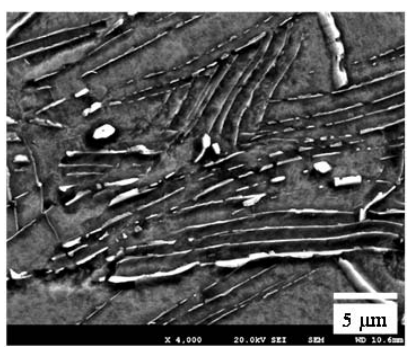

c) Sample C

Figure 4: Delta structure after compression tests and details of deformation.

The final $\delta$-phase amount was observed to be heavily dependent on the test temperature and strain rate. As expected, sample B deformed at $1020{ }^{\circ} \mathrm{C}$, with its lowerat a strain rate of $0.01 \mathrm{~s}^{-1}$ revealsing a much lower $\delta$-phase content, while sample A deformed at $960^{\circ} \mathrm{C}$ and $0.001 \mathrm{~s}^{-1}$, seemingly preserving the existing $\delta$-phase amount or precipitating even further. In contrast, sample $\mathrm{C}$ deformed at $1020{ }^{\circ} \mathrm{C}$ at the highest strain rate of $1 \mathrm{~s}^{-1}$, therefore exhibitsing a similar $\delta$-phase content to sample A. At a higher strain rate, less time is needed to dissolve $\delta$-phase at a temperature above $\delta$-solvus, as shown in Fig. 5.

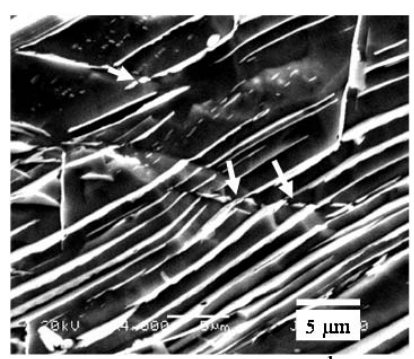

a) Sample A $\left(960{ }^{\circ} \mathrm{C}, 0.001 \mathrm{~s}^{-1}\right)$

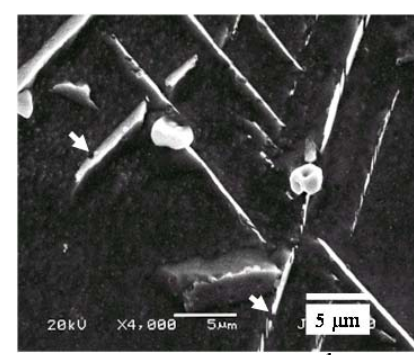

b) Sample B $\left(1020{ }^{\circ} \mathrm{C}, 0.01 \mathrm{~s}^{-1}\right)$

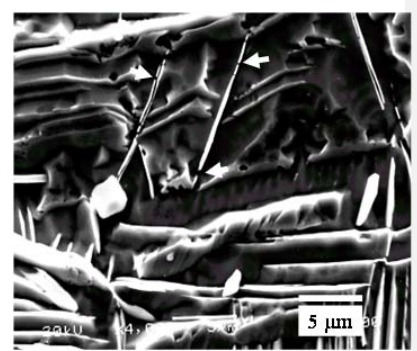

c) Sample $\mathrm{C}\left(1020^{\circ} \mathrm{C}, 1 \mathrm{~s}^{-1}\right)$

Figure 5: Comparison of delta phase structure after compression tests and details of deformation.

\section{Overview of the Flow Curves}

The flow curves were immediately available for analysis upon completion of the compression tests. Fig. 6 shows a selection of the flow curves obtained from one set of 10 tests. Generally speaking, the flow curves reveal a strong DRX response characterized by a single-peak behavior, in accordance with previous studies by Wang et al. (2009) where the flow curves exhibit a rapid increase to a peak at a

Con formato: Sin Resaltar 
critical strain, followed by slow-flow softening regardless of the deformation temperature. Such features of the flow curves for the delta-processed superalloy 718 correspond to those for alloys with low-stacking fault energy (SFE), which implies the occurrence of the DRX phenomenon during hot deformation (Wang et al., 2011). A natural dependence on the Zener-Hollomon parameter ( $Z$, the temperature compensated strain rate) may also be observed, where higher stress levels are attained by increasing $\mathrm{Z}$.

The flow curves of the samples which did not receive DP heat treatment prior to deformation may also be found in Fig. 6. Although these samples reveal an increase in stress after reaching an initial peak stress and maintaining a plateau at that level for some time, such an increase is not observed for samples with DP heat treatment. The behavior of these samples will be discussed in detail in the following sections. Apart from this exceptional case, it must be noted that samples which were not delta processed revealed lower peak stress values than their counterparts. This is associated with the low amount of $\delta$-phase in these samples.

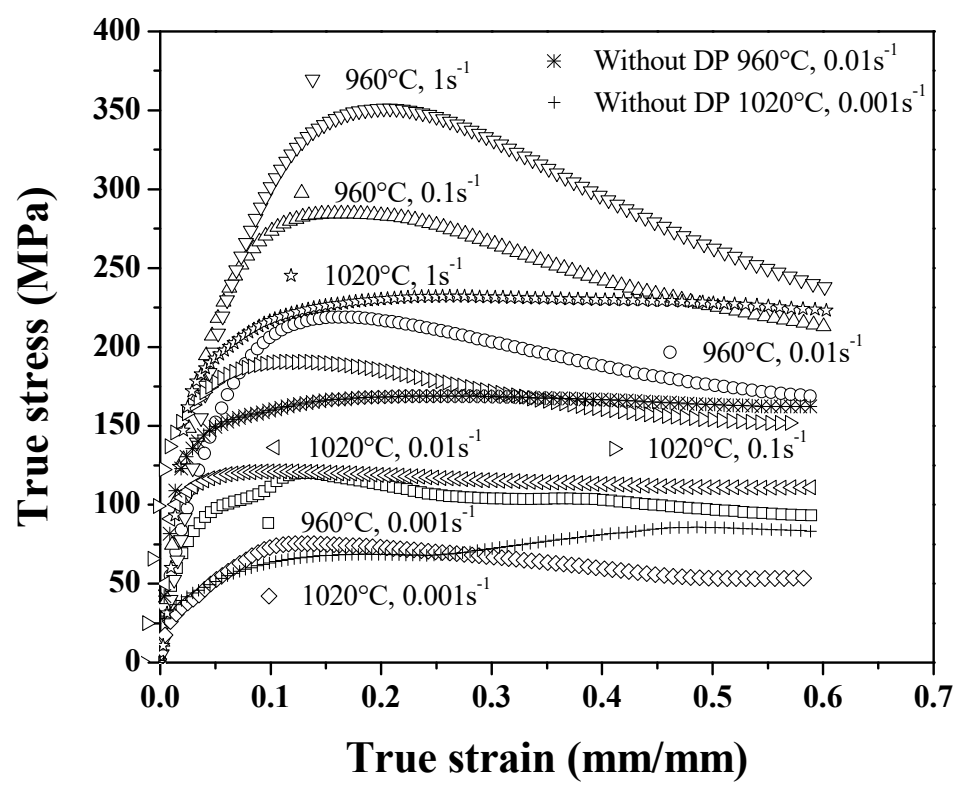

Figure 6: Flow curves with and without DP 


\section{Modeling of the Flow Curves}

\section{Peak Stress Modeling through the Apparent Approach:}

A widely used approach proposed by Sellars and Tegart (1966) connecting the peak stress $\left(\sigma_{\text {peak }}\right)$ to the temperature compensated strain rate $_{2}$ - is also known as the Zener-Hollomon parameter $(\mathrm{Z})_{2}$-and is given in Eq. (1) to (3).

$$
\begin{aligned}
& A \sinh \left(\alpha \sigma_{\text {peak }}\right)^{n}=\dot{\varepsilon}\left(\exp -\frac{Q}{R T}\right)=Z \\
& A^{\prime} \sigma_{\text {peak }}{ }^{\prime}=Z \\
& A^{\prime} \exp \left(\beta \sigma_{\text {peak }}\right)=Z
\end{aligned}
$$

where $\mathrm{A}, \mathrm{A}^{\prime}, \mathrm{A}^{\prime \prime}, \mathrm{n}, \mathrm{n}^{\prime}, \beta$, and $\alpha$ are material constants. $Q$ is the activation energy of deformation, $\mathrm{R}$ is the universal gas constant $\left(\mathrm{in} \mathrm{Jmol}^{-1} \mathrm{~K}^{-1}\right), \mathrm{T}$ is absolute temperature $(\mathrm{K})$, and $\dot{\varepsilon}$ is the strain rate.

Eq. (1), Eq. (2), and Eq. (3) are referred to as "Hyperbolic Sine Law", "Power Law", and "Exponential Law" respectively. While hyperbolic sine law (Eq. (1)) may be implemented in a wide range of deformation conditions, power law and exponential law are used to describe flow stresses in lower and higher stress ranges, respectively. $\alpha$ is usually referred to as an adjustable stress multiplier and chosen based on the behavior of $\ln \varepsilon$ vs. $\ln (\sinh (\alpha \sigma))$. It is also possible to regard $\alpha$ as the inverse stress at which Eq. (2) starts to break.

The plots and parameters were then built according to the flow curves of the total 20 tests. Slopes of the plots $\ln \dot{\varepsilon}$ vs $\sigma_{\mathrm{p}}, \ln \dot{\varepsilon}$ vs $\ln \sigma_{\mathrm{p}}$, and $\ln \dot{\varepsilon}$ vs $\ln \sinh \left(\alpha \sigma_{\mathrm{p}}\right)$ may be used to obtain $\beta, \mathrm{n}^{\prime}$, and $\mathrm{n}$, respectively. It is then possible to retrieve $\alpha$ in Eq. (1) via:

$$
\alpha=\beta / n^{\prime} \quad \text { (Eq. 4): }
$$

According to Fig. 7, the average values of $\beta$ and n' are 0.025 and 5.075 respectively, with alpha therefore given as 0.006104 . 


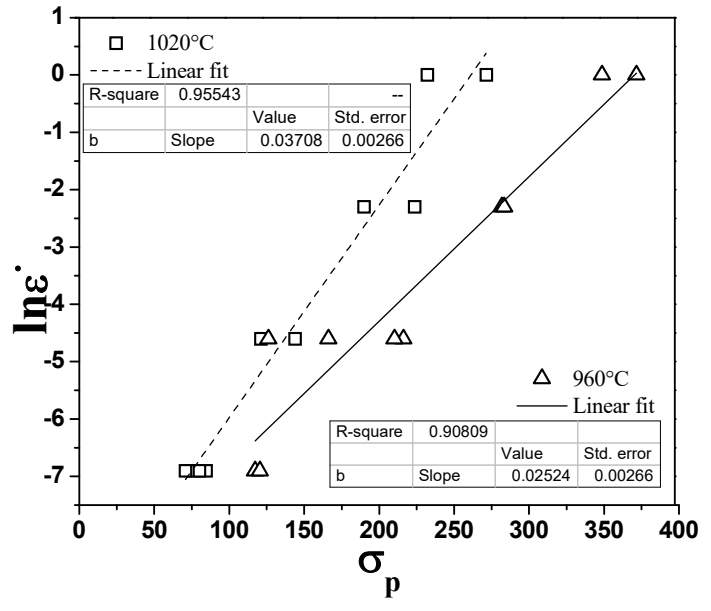

a)

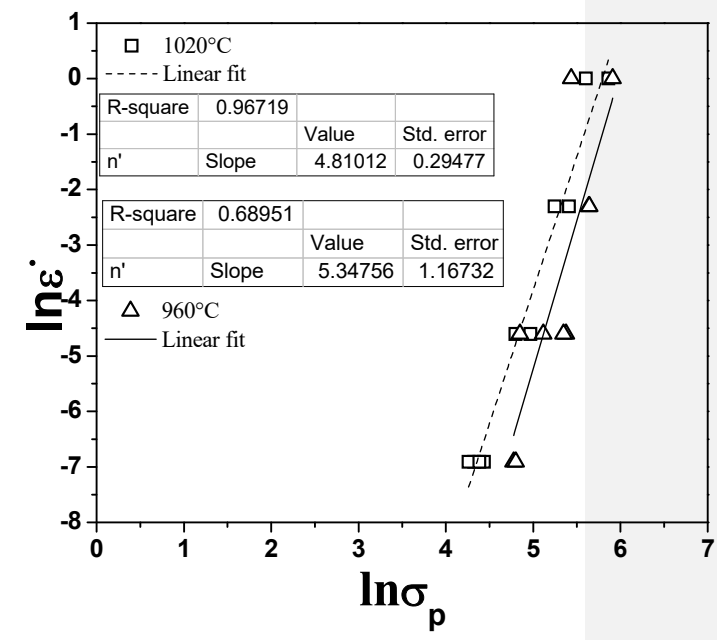

b)

Figure 7: Plots used to derive $\beta$ (a) and n' (b)

Similar to $\beta$ and n', exponent $\mathrm{n}$ may be found from the $\ln \dot{\varepsilon}$ vs $\ln \sinh \left(\alpha \sigma_{\mathrm{p}}\right)$ plot by linear regression within the respective temperature data points, ranging from 1 to 5 . According to Rodriguez-Calvillo et al. (2014), the n-value is a parameter that may be dependent on temperature, although this effect may be neglected, with the average value usually considered. This is shown in Fig. 8-a, with the $\mathrm{n}$ values found to be 3.52 and 4.23 for 960 and $1020^{\circ} \mathrm{C}$ respectively, resulting in an average of 3.88 .

In order to determine the activation energy, a partial differentiation of the reordered forms of Eqs. (1), (2), and (3) at a constant strain rate yields the following equations, respectively:

$$
\begin{aligned}
& Q_{H W}=R n^{\prime}\left[\frac{\partial \ln \sigma_{p}}{\partial\left(\frac{1}{T}\right)}\right]_{\dot{\varepsilon}} \\
& Q_{H W}=R \beta\left[\frac{\partial \sigma_{p}}{\left.\partial\left(\frac{1}{T}\right)\right]_{\dot{\varepsilon}}}\right. \\
& Q_{H W}=R n\left[\frac{\partial \ln \sinh \left(\alpha \sigma_{p}\right)}{\partial\left(\frac{1}{T}\right)}\right]_{\dot{\varepsilon}}
\end{aligned}
$$

The highest correlation coefficient $\left(\mathrm{R}^{2}\right)$ of the regression treatments above was considered after a selection of the activation energy of deformation, with this a value of $461 \mathrm{~kJ} / \mathrm{mol}$ via Eq. (7). This value is for Inconel 718 subjected to DP and is in accordance with those reported by Wang et al. (2011) and Si et al. (2015), at $467 \_\mathrm{KJ} / \mathrm{mol}$ and $468.77 \mathrm{~kJ} / \mathrm{mol}$, respectively.

Finally, the Zener-Hollomon parameter, $\mathrm{Z}$ and $\sigma_{\mathrm{p}}$ may be applied fitted via Eq. (1). This is shown in Fig. 8-b, with the constant $A$ found to be $8 \cdot 10^{16} \mathrm{~m}^{-2}$ accordingly. 


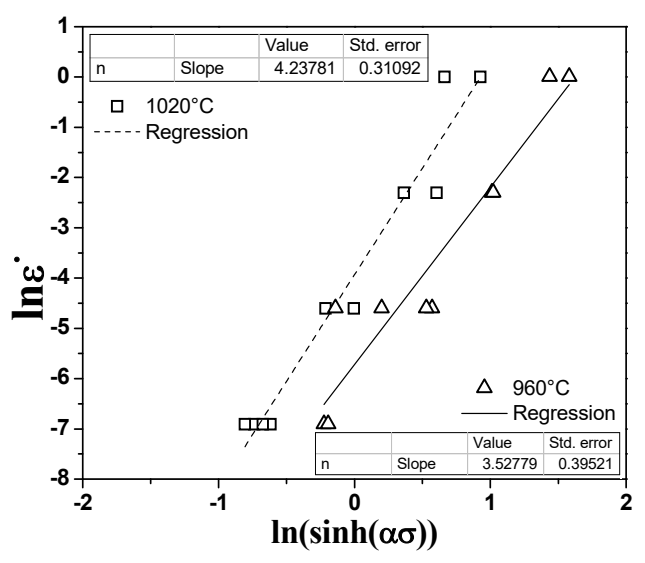

a)

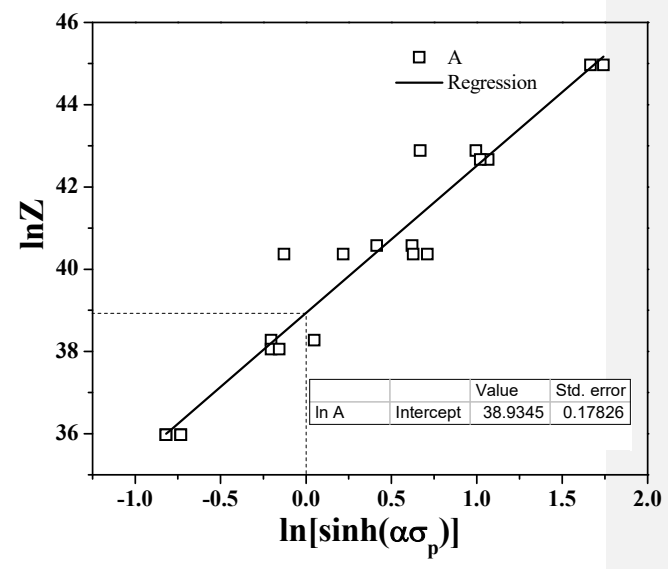

b)

Figure 8: Plots to find the constant a) $n$, b) $A$ in apparent approaches.

\section{Peak Stress Modeling - Physically-Based Approach:}

Cabrera et al. (1996) are among those to have shown that when the temperature dependence of the self-diffusion coefficient and the elastic modulus are taken into account, it is possible to take creep exponent as 5 and use self-diffusion activation energy instead of the activation energies found in the previous section. This approach is reliable as long as the glide and climb of dislocations are the main mechanisms of deformation, and here it is claimed to be so, in accordance with the conclusions made by Thomas et al. (2006). Introducing the above-mentioned modifications to the Eq. (1) and re-writing for strain-rate affects Eq. (1) as followsbecomes:

$$
\frac{\dot{\varepsilon}}{D(T)}=B\left[\sinh \left(\alpha^{\prime} \frac{\sigma}{E(T)}\right)\right]^{n}
$$

Where the creep exponent $\mathrm{n}=5, E(T)$ is Young's modulus and $D(T)$ is the coefficient of self-diffusion, both given as functions of temperature.

$D(T)$ and $E(T)$ may be retrieved from the Eqs. (9), (10) and (11):

$$
\begin{aligned}
& D(T)=D_{o v} \exp \left(\frac{-Q_{v}}{R T}\right) \\
& E=2(1-v) \mu \\
& \mu=\left[\mu_{0}\left(1-\left(\frac{T-300}{T_{M}}\right)\right) \frac{T_{M}}{\mu_{0}} \frac{d \mu}{d T}\right]
\end{aligned}
$$


Here, $\mu_{0}, Q_{s d}$ and $D_{0}$ have been described by Frost and Ashby (1982), with Nickel giving the diffusion constant $\mathrm{D}_{0}$ and the self- diffusion activation energy as $1.6 \times 10^{-4} \mathrm{~m}^{2} / \mathrm{s}$ and $285 \mathrm{~kJ} / \mathrm{mol}$, respectively. The Poisson's ratio $v$ was taken as $1 / 3$.

The physically-based material constants may be found by directly fitting the Eq. (8) to the experimental data obtained. The resulting material constants and the peak stress dependence of the material are summarized in Table 2 and Fig. 9 respectively.

Table 2. Parameter values for the physically-based model

\begin{tabular}{ccc}
\hline & Parameters & \\
\hline & $\alpha^{\prime}$ & $B$ \\
With DP & 1155.78 & $1 \mathrm{E}+20$ \\
Without DP & $\mathbf{1 5 9 6 . 6 2}$ & $\mathbf{1 E}+\mathbf{2 0}$ \\
\hline
\end{tabular}

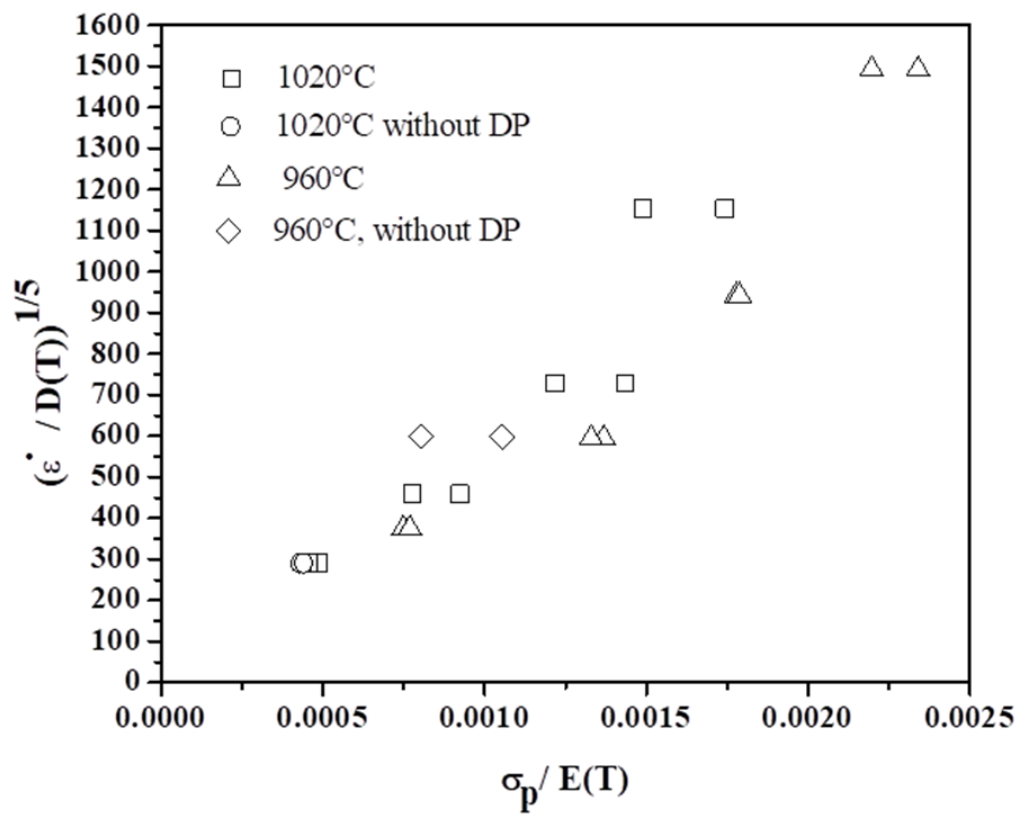

Figure 9: Dependence of the peak stress on the strain rate and temperature on the basis of Eq. (9). Parameters are determined with data points at 1020 and $960^{\circ} \mathrm{C}$ for DP and non-DP separately. 


\section{Modeling of work hardening and recovery}

Models describing the behavior of metals undergoing dynamic recovery generally consider that the dislocation density is a result of the balance between dislocation generation and storage during work hardening and annihilation during dynamic recovery. This is described in Eq. (12) below:

$$
\frac{d \rho}{d \varepsilon}=(d \rho / d \varepsilon)_{\text {stored }}-(d \rho / d \varepsilon)_{\text {recovered }}
$$

A combination of the approaches taken by Bergstrom (1970) and Estrin and Mecking (1984) results in an expression that corresponds to Eq. (12), which may be given by

$$
d \rho / d \varepsilon=U-\Omega_{\rho}
$$

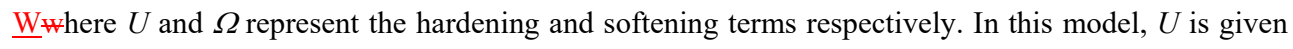
as the rate of dislocation immobilization and $\Omega_{\rho}$ is given as the probability/rate of re-mobilization in sessile dislocations.

In addition to this, Eq. (14) and Eq. (15) describe the flow stress in terms of the plastic strain. The derivation of these equations is given by Jonas et al. (2009).

$$
\begin{aligned}
& \sigma=\left(\sigma_{\text {sat }}^{2}-\left(\sigma_{\text {sat }}^{2}-\sigma_{0}^{2}\right) \exp (-\Omega \varepsilon)\right)^{1 / 2} \\
& \sigma \frac{d \rho}{d \varepsilon}=0.5 \Omega \sigma_{\text {sat }}^{2}-0.5 r \sigma^{2}
\end{aligned}
$$

When $\sigma_{0}$, the yield stress at high temperature $\left(\sigma_{0}=\alpha^{\prime} \mu \mathrm{b}{\sqrt{\rho_{0}}}_{0}\right)$ is considered to be zero, therefore-Eq. (14) becomes:

$$
\sigma=\sigma_{d r v} \sqrt{(1-\exp (-\Omega \varepsilon))} \quad(\mathrm{Eq} \cdot(16)
$$

where

$$
\sigma_{d r v}=\alpha^{\prime} \mu b \sqrt{U / \Omega}
$$

Based on Eq. (16), $\Omega$ may be calculated by least squares fit and $(\alpha b)^{2} U$ may be calculated in turn based on

$$
\left(\alpha^{\prime} b\right)^{2} U=\sigma_{d v r}^{2} \Omega / \mu^{2}
$$

The hardening and softening may be also expressed as a function of the Zener-Hollomon parameter through the following relationships:

$$
\left(\alpha^{\prime} b\right)^{2} U=K_{U} Z^{m_{U}}
$$

and

$\Omega=K_{\Omega} Z^{m_{\Omega}}$ (Eq-20). 
This representation is depicted in Fig. 10. It may be seen that in general terms the recovery parameter decreases somewhat as $\mathrm{Z}$ increases, while the hardening term increases with increasing $\mathrm{Z}$. However, $\mathrm{U}$ should remain constant given that the grain structure is fine enough and fine particles exist in the structure, and therefore the mean free path of dislocations is geometrically limited.

Although more tests would be necessary for further comparison, based on the data obtained here it may be said that hardening term of the delta processed samples show a lower $\mathrm{Z}$ sensitivity, proving that the $\delta$-precipitates increase the geometrical limitation on the mean free path of dislocations. Table 3 shows the results obtained for $K$ and $m$ constants for the whole data set without accounting for the deltaprocessed materials. 
Table 3. $K$ and $m$ constants in Eqs (19) and (20)

\begin{tabular}{ccc}
\hline \multirow{2}{*}{ Parameters } & \multicolumn{2}{c}{ Constants } \\
& $\mathbf{K}$ & $\mathbf{~ m}$ \\
\hline $\boldsymbol{\Omega}_{\text {sat }}$ & 488.09 & -0.05 \\
$\mathbf{U}_{\text {sat }}(\boldsymbol{\alpha b})^{2}$ & $6.8 \mathrm{E}-07$ & 0.16 \\
\hline
\end{tabular}
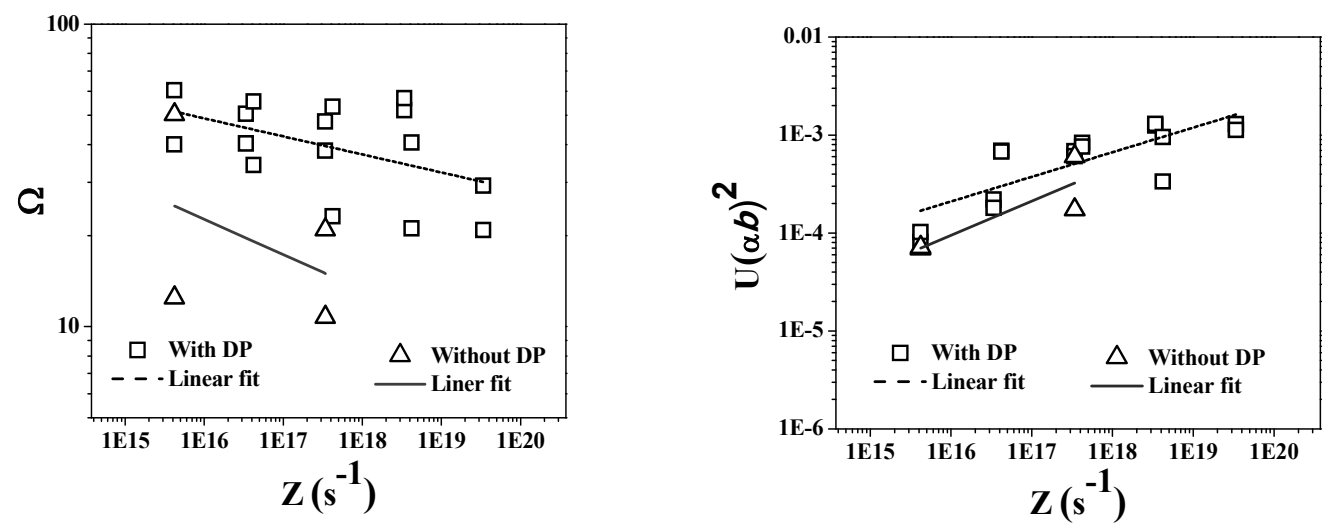

Figure 10: Parameters associated with softening (left) and hardening (right) terms in Eqs. (19) and (20) respectively. The figures show the comparison between delta processed and non-delta processed samples.

\section{Dynamic Recrystallization (DRX) Modeling}

The peak strain $\varepsilon_{\mathrm{p}}$ and peak stress $\sigma_{\mathrm{p}}$ are identified with the experimental curve point where $\theta=$ $d \sigma / d \varepsilon$ drops to zero. The recrystallized volume fraction here is responsible for the difference between the curves $\sigma_{\mathrm{DRX}}$ and $\sigma_{\text {Recovery }}$, therefore the recrystallized volume fraction may be obtained by correlating this with the Avrami approach:

$$
X=1-\exp \left(-B t^{k}\right)
$$

where $t$ is time, and $k$ and $B$ are parameters associated with the nucleation mechanisms and nucleation rate and growth respectively. This calculation is performed for each hot flow curve for the section from $\sigma_{\mathrm{p}}$ to $\sigma_{\mathrm{ss}}$. Due to numerical issues, $t$ and $\mathrm{B}$ are usually related in terms of the time needed for $50 \%$ recrystallization $\left(t_{50 \%}\right)$. In this case, Eq. $(21)$ is written as follows:

$$
X_{D}=1-\exp \left(-0.693\left[\frac{\varepsilon-\varepsilon_{p}}{\varepsilon t_{50 \%}}\right]^{k}\right)
$$

\section{Where:}

$t=\left(\varepsilon-\varepsilon_{\rho}\right) / \dot{\varepsilon}_{-}(\mathrm{Eq} .23)$

and 
$t_{50 \%}=[0.693 / B]^{1 / k^{\prime}}$

This latter expression can be empirically obtained through:

$$
t_{50 \%}=B \varepsilon^{n} \exp \left(\frac{Q_{r e c}}{R T}\right)
$$

Fig. 11 shows the evolution of the $\mathrm{k}$ exponent with respect to Z. Here it may be observed that $k$ is not a function $Z$. The Avrami exponent usually reaches values of 1-2 for nucleation of recrystallized grains in grain boundaries that are collar shaped (Christian, 1981), with the average value 0.934 in this case. This value may be accepted as an indicator of the dominant grain boundary nucleation of DRX. The parameters $k_{t 50 \%}, n_{t 50 \%}$ and $Q_{t 50 \%}$, defining the point of $\mathrm{t}_{50 \%}$, are summarized in Table 4.

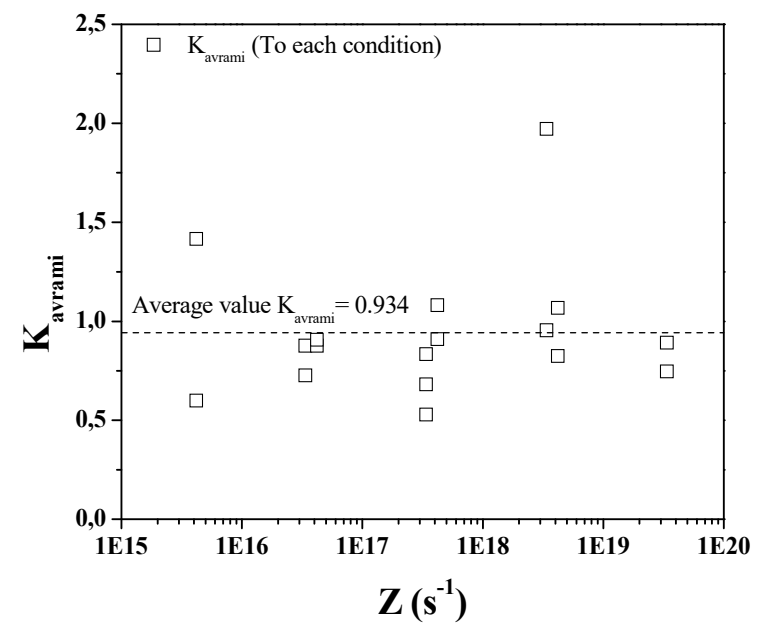

Figure 11. $\mathrm{K}_{\text {avrami }}$ evolution with $\mathrm{Z}$

Table 4. Parameters, $K_{t 50 \%}$ (B”), $n_{t 50 \%}$ and $Q_{t 50 \%}$, for different groups of test conditions

\begin{tabular}{llll}
\hline Test conditions & $\mathbf{k}_{\mathbf{t 5 0} \%}$ & $\mathbf{n}_{\mathbf{t 5 0} \%}$ & $\mathbf{Q}_{\mathbf{r e c}} \mathbf{( 5 0 \% )}(\mathbf{J} / \mathbf{m o l})$ \\
\hline $\mathbf{A l l}$ & $1.1 \mathrm{E}-06$ & 0.89 & 124952 \\
$\mathbf{9 6 0}^{\circ} \mathbf{C}$ & $2.51 \mathrm{E}-07$ & 0.88 & 125209 \\
$\mathbf{1 0 2 0}^{\circ} \mathbf{C}$ & $2.71 \mathrm{E}-06$ & 0.88 & 125209 \\
$\mathbf{0 . 0 0 1}$ & $5.54 \mathrm{E}-07$ & 1.18 & 109859 \\
$\mathbf{0 . 0 1}$ & $6.28 \mathrm{E}-05$ & 0.44 & 145637 \\
$\mathbf{0 . 1}$ & $5.34 \mathrm{E}-10$ & 0.5 & 252430 \\
\hline
\end{tabular}

After the critical point where DRX starts, the softening is accepted to be proportional to the volume fraction of the regions that underwent DRX. In this region, the drop from the maximum stress $\sigma_{\mathrm{p}}$ to the steady state $\sigma_{\mathrm{ss}}$ may be expressed by: 


$$
\sigma=\sigma_{p}-\left(\sigma_{p}-\sigma_{s s}\right)\left[1-\exp \left[-0.693\left[\frac{\varepsilon-\varepsilon_{p}}{\dot{\varepsilon} t_{50 \%}}\right]^{k^{\prime}}\right.\right.
$$




\section{Predicted and experimental flow curves}

Finally, the obtained material constants were used to construct the individual predicted flow curves as a function of strain. In the final simulation, only the physically-based peak stress modeling approach is used. Figs. 12 and 13 summarize the results together with the experimental flow curves for a set of 10 tests.

Since the tests are conducted at four different strain rates and two specific temperatures, it may be said that the material constants obtained via both approaches are attached and limited due to the lack of further testing conditions and special care should be applied when using them. For the non-delta-processed samples both peak stress modeling approaches (i.e. physically based and apparent) fail to predict the peak stress. This is thought to be due to the late precipitation of specific phases and unusual DRX behavior of these samples.

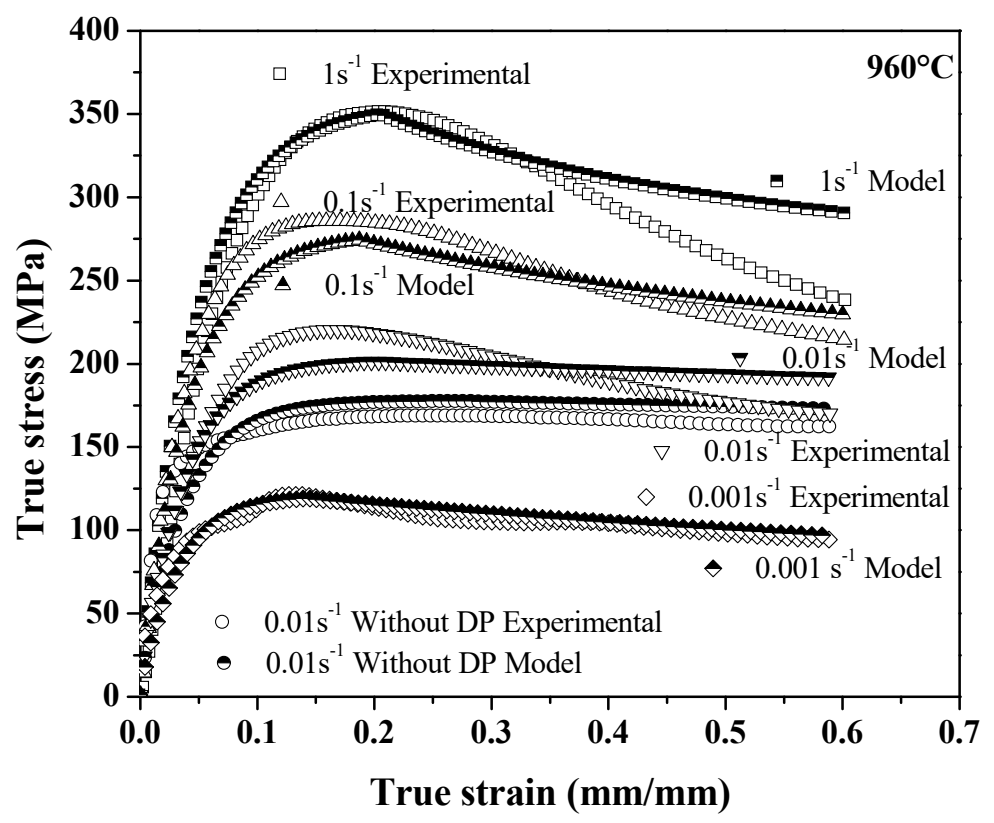

Figure 12. Comparison of the flow curves (experimental and model) Deformed samples at $960{ }^{\circ} \mathrm{C}$. 


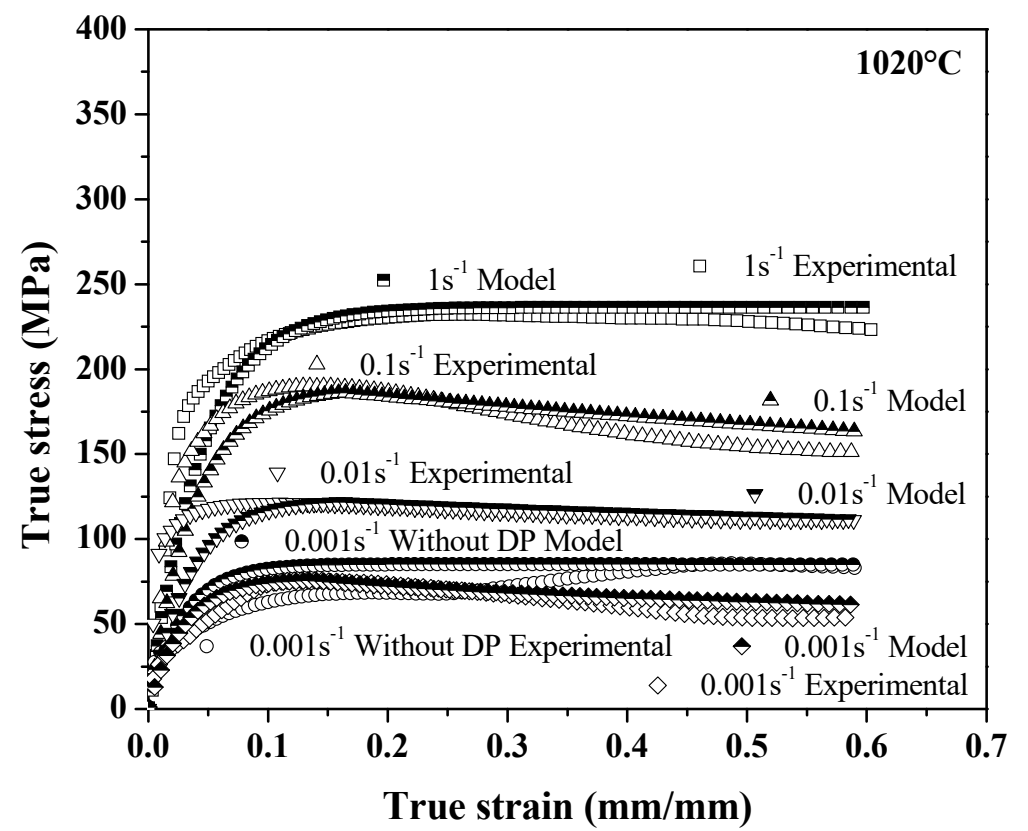

Figure 13. Comparison of the flow curves (experimental and model) Deformed samples at $1020{ }^{\circ} \mathrm{C}$. 


\section{CONCLUSIONS}

Hot deformation behavior of delta-processed Inconel 718 has been investigated, with the microstructure of the alloy before and after the delta processing, before the deformation, and after the deformation tracked. Representative microstructures are outlined in the text, while the flow curves obtained have been modeled using two different approaches referred to as "Apparent" and "PhysicallyBased". The stress strain behavior has been predicted within acceptable limits by both approaches. In the final simulation, however, only the physically-based model was taken into account since the predictive capability of this approach was found to be slightly more reliable than the apparent approach. For the nondelta-processed samples both approaches fail to predict the flow behavior in detail since these samples revealed dynamic precipitation, which is not covered by either of these modeling approaches.

The delta processing may facilitate grain uniformity and grain refinement during and after high temperature deformation. Furthermore, when the $\delta$ phase is obtained prior to the deformation, this phase may undergo partial dissolution and fracture during the hot deformation. As a result, fine and distributed $\delta$ particles may be obtained near grain boundaries which may act as nucleation sites for dynamic recrystallization. The mechanism which delays grain growth after dynamic recrystallization has been found to be Zener pinning.

Apart from the natural single peak DRX behavior observed, some specimens that were deformed at low strain rates and temperatures below $\delta$-solvus exhibited secondary humps on the flow curves which are thought to have originated from the $\mathrm{M}_{23} \mathrm{C}_{6}$ carbides rich in $\mathrm{Nb}$ and Mo. This phenomenon shall be investigated in depth in our future studies.

\section{ACKNOWLEDGEMENTS}

PPK is grateful to Conacyt Mexico for providing financial support for the developing of this project (Grant: 277663). The authors would also like to acknowledge FRISA Forjados S.A. de C.V for supplying the material.

\section{REFERENCES}

Agnoli, A., Bernacki, M., Logé, R., Franchet, J. M., Laigo, J., \& Bozzolo., N., 2015. Selective Growth of Low Stored Energy Grains During $\delta$ Sub-solvus Annealing in the Inconel 718 Nickel-Based Superalloy. Metallurgical and Materials Transactions A, 46 (9), 4405-4421.

Azarbarmas, M., Aghaie-Khafri, M., Cabrera, J. M., \& Calvo, J., 2016. Microstructural evolution and constitutive equations of Inconel 718 alloy under quasi-static and quasi-dynamic conditions. Materials \& Design, 94, 28-38.

Bergström, Y., 1970. A dislocation model for the stress-strain behavior of polycrystalline $\alpha$-Fe with special emphasis on the variation of the densities of mobile and immobile dislocations. Materials Science and Engineering, 5 (4), 193-200.

Cabrera, J. M., Jonas, J. J., \& Prado, J. M., 1996. Flow behavior of medium carbon microalloyed steel under hot working conditions. Materials Science and Technology, 12 (7), 579-585.

Cheng, M., Zhang, H. Y., \& Zhang, S. H., 2012. Microstructure evolution of delta-processed IN718 during holding period after hot deformation. Journal of Materials Science, 47 (1), 251-256.

Christian, J. W., 1981. The theory of transformations in metals and alloys. Newnes. Ed. Pergamon Press, Oxford, chapters. 1 (1-22) and 12; 529-552.

Estrin, Y., \& Mecking, H., 1984. A unified phenomenological description of work hardening and creep based on oneparameter models. Acta Metallurgica, 32 (1), 57-70.

Frost, H. J., \& Ashby, M. F., 1982. The Plasticity and Creep of Metals and Ceramics. Pergammon Press, Oxford. 54-55. 
Hongbo, D., \& Gaochao, W., 2015. Effect of Deformation Process on Superplasticity of Inconel 718 Alloy. Rare Metal Materials and Engineering, 44 (2), 298-302.

Hussain, M. Z., Li, F., Wang, J., Yuan, Z., Li, P., \& Wu, T., 2015. Determination of constitutive equation for thermomechanical processing of Inconel 718 through double multivariate nonlinear regression analysis. Journal of Materials Engineering and Performance, 24 (7), 2744-2756.

Lin, Y. C., He, M., Zhou, M., Wen, D. X., \& Chen, J., 2015. New constitutive model for hot deformation behaviors of Nibased superalloy considering the effects of initial $\delta$ phase. Journal of Materials Engineering and Performance, 24 (9), $3527-3538$.

Lin, Y. C., Li, K. K., Li, H. B., Chen, J., Chen, X. M., \& Wen, D. X., 2015. New constitutive model for high-temperature deformation behavior of inconel 718 superalloy. Materials \& Design, 74, 108-118.

Lin, Y. C., Wen, D. X., Deng, J., Liu, G., \& Chen, J., 2014. Constitutive models for high-temperature flow behaviors of a Nibased superalloy. Materials \& Design, 59, 115-123.

Ning, Y., Huang, S., Fu, M. W., \& Dong, J., 2015. Microstructural characterization, formation mechanism and fracture behavior of the needle $\delta$ phase in Fe-Ni-Cr type superalloys with high Nb content. Materials Characterization, 109, $36-42$.

Nöhrer, M., Zamberger, S., \& Leitner, H., 2013. Strain-Induced Precipitation Behavior of a Nb-Ti-V Steel in the Austenite Phase Field. Steel Research International, 84 (9), 827-836.

Rodriguez-Calvillo, P., Boulaajaj, A., Perez-Sine, M., Schneider, J., \& Cabrera, J. M., 2014. On the hot working of FeSi ferritic steels. Materials Science and Engineering: A, 606, 127-138.

Sellars, C. M., \& McTegart, W. J., 1966. On the mechanism of hot deformation. Acta Metallurgica, 14 (9), 1136-1138.

Si, J. Y., Liao, X. H., Xie, L. Q., \& Lin, K. R., 2015. Flow behavior and constitutive modeling of delta-processed Inconel 718 alloy. Journal of Iron and Steel Research, International, 22 (9), 837-845.

Thomas, A., El-Wahabi, M., Cabrera, J. M., \& Prado, J. M., 2006. High temperature deformation of Inconel 718. Journal of Materials Processing Technology, 177 (1), 469-472.

Wang, Y., Shao, W. Z., Zhen, L., \& Zhang, B. Y., 2011. Hot deformation behavior of delta-processed superalloy 718. Materials Science and Engineering: A, 528 (7), 3218-3227.

Wang, Y., Shao, W. Z., Zhen, L., Yang, C., \& Zhang, X. M., 2009. Tensile deformation behavior of superalloy 718 at elevated temperatures. Journal of Alloys and Compounds, 471 (1), 331-335.

Wang, Y., Zhen, L., Shao, W. Z., Yang, L., \& Zhang, X. M., 2009. Hot working characteristics and dynamic recrystallization of delta-processed superalloy 718. Journal of Alloys and Compounds, 474 (1), 341-346.

Zhang, H. Y., Zhang, S. H., Cheng, M., \& Li, Z. X., 2010. Deformation characteristics of $\delta$ phase in the delta-processed Inconel 718 alloy. Materials Characterization, 61 (1), 49-53.

Zhang, S. H., Zhang, H. Y., \& Cheng, M., 2011. Tensile deformation and fracture characteristics of delta-processed Inconel 718 alloy at elevated temperature. Materials Science and Engineering: A, 528 (19), 6253-6258. 